\title{
Georgette Fadel
}

á estou, de novo, sentada numa cadeira daqui a poucos minutos terei que me levantar. Quando eu me levantar terei que fazer algo que signifique algo, terei que romper uma parede do nada e apontar alguma direção. Tenho medo de fracassar, medo que finalmente descubram a farsa que eu sou. Que descubram que não sei nada, que chegou o momento em que minha boa sorte me abandonará. Olho para a Bel, confio nela. Muito. A ponto de querer me entregar a uma melancoliazinha e me atirar no peito dela numa confissão: "Eu não sou Hamlet, parceira!! Eu não represento mais nenhum papel. Meus pensamentos sugam o sangue das imagens...”. Me contenho porque sei que esperam alguma firmeza de mim, um pouco de coragem.

Quando Cibele e Bel foram me chamar em minha casa para esse trabalho com docinhos e vinho, eu estava tranqüila e sabia da minha coragem de enfrentar o desconhecido. "Pois bem, Lady Maria" - diz Elizabeth de Schiller "E o que é que você tem a me dizer? Você pediu tanto este encontro, pois bem, eu estou aqui!" Pois bem, Elizabeth: workshops, improvisações, workshops, improvisações. Um "primeiro momento inseguro" que se transformou em "segundo momento de semanas de acerto", que gerou "a hora da verdade", que culminou com "os dias contados" até a "recuperação súbita", que vomitou "a estréia".

A longa estrada das escolhas. A longa estrada do pensar e refletir os motivos das escolhas:

Escolhemos no início trabalhar -as duas atrizes - as duas rainhas.

Escolhemos que os camarins seriam cena.

Escolhemos a arena.

Escolhemos um certo tom ao abordar Maria, presente de certa maneira na estrutura do texto de Schiller. Um segredo, uma caixa com as coisas dela: o que sobrou de sua realeza.

Escolhemos um jogo das atrizes de cena dentro da cena (que pra nós virou "a cebola"), que revelaria camadas da problemática de Elizabeth.

Escolhemos que, sobre a energia de Mortimer (personagem importante do texto de Schiller) se desenvolveria uma atriz apaixonada.

Escolhemos que a procura do coração seria guia de tudo.

Escolhemos que o encontro seria como no texto de Schiller.

Escolhemos nós mesmas responsabilizarmo-nos pela dramaturgia, correndo todos os ris-

Georgette Fadel é atriz e encenadora. 
cos dos rombos possíveis, mas intuindo que eles seriam uma característica importante dessa dramaturgia.

Escolhemos, em certo momento já avançado, que eu construiria Elizabeth e Bel, Maria, pelo tempo e pela clareza da história que precisava ser contada.

Escolhemos um labirinto para os nossos pés - um centro a se chegar, a prisão de Maria o cérebro de Elizabeth.

Escolhemos os objetos que foram habitando e, portanto, revelando a margem do rio: os roupóes da avó querida da Bel; o colar; os grampos; a touca; a peruca; o cabide; os espelhos; as toalhas de banho; o coração-bexiga (que foi trazido à cena numa improvisação apaixonada pela Cibele vestida de branco regando com sangue uma plantinha); o anel de coração; a caixa; os textos; o livro de Schiller, o autor, o iluminado; o talco; o sangue explícito (groselha, karo, anilina); o trompete; a munhequeira na mão; o garfo que perfuraria a mão não fosse a munhequeira.

Escolhemos que as coisas das nossas vidas cotidianas poderiam invadir literal e literariamente a nossa criação.

Escolhemos que seria bom cantar.

Escolhemos que seria o Lincoln. Certos momentos, certas palavras pediam a elevação, a estranheza e o grifo da música que o Lincoln sabe bem fazer. Eu sabia bem disso por ter tido a graça de cantar com ele as falas da Stela do Patrocínio que ele musicou respeitando certa cadência e melodia presentes nessas falas.

Escolhemos que haveria um piano e um pianista em cena.

Escolhemos que o pianista (aquele ser que teria que ter permeabilidade pra absorver nossas loucuras, teria que tocar muito bem pra entender as estruturas que o Lincoln criou e até improvisar sobre elas em alguns momentos, que fosse uma pessoa legal de se conviver, tivesse um olhar aberto e sensível para o teatro, afinal a criatura estaria em cena e teria que saber disso...) seria Manuel Pessoa.
Escolhemos logo que seria a Luaa, mulher-ponte costurando a comunicação das partes. Ela, além das questões básicas e técnicas do ensaio - a cafeteira, o som, as anotações, o ponto, o papelão em torno da lâmpada pra tentar o foco - era, além disso, a companheira firme do coração que sabia das nossas fragilidades e não deu a menor bola pra elas. Alimentando sempre o que apontava para o futuro.

Escolhemos os animais que norteariam os sentimentos e os gestos: a serpente e o cavalo.

Escolhemos, lá pelo meio de tudo, ter a Tica por perto que é a grande responsável pelo quanto eu a Bel gostamos de dançar sem medo. Graças a uma história longa com ela, anterior e durante esse trabalho, é que conseguimos improvisar com alguma consciência do corpo e do espaço. Com ela entramos na noite percorrendo quilômetros no labirinto até ele gostar da gente, com ela a massagem, a respiração, os sentimentos e pensamentos se dando conta de si. Foi ela quem preservou, às vezes só com a presença, um espaço vazio dentro de nós, a lembrança da Terra firme e confiável, o espaço para o desenvolvimento da gestualidade que nascia dos animais que escolhemos.

E tantas outras escolhas. Do melhor momento para tocar em um assunto, do acreditar ou não em uma idéia, da cor do batom, do vencer o cansaço, de buscar a facilidade ou a dificuldade, da quantidade de grampos no cabelo ou na peruca, do entregar-se completamente agora ou perder mais um pouquinho de tempo na vida.

Dentro de mim as questóes do Poder e da Morte, desdobradas em competição, inveja, culpa e medo, girando e tomando os meus dias. A relação com todos no cotidiano dos ensaios ia explicitamente ancorando situações, emoções e pensamentos dos reinos das duas rainhas. Muitas vezes durante esses meses, me vi, fora de lá dos nossos encontros, incorporando algumas falas, jeitos, procedimentos de cada um que habitou esse espaço tão real da criação. Sem um controle tão racional, com a convivência inten- 
sa, foi possível e inevitável que um pequeno mundo se formasse dessas presenças. Foi uma expansão de territórios possíveis da minha criação. Fisicamente isso me veio em forma de ângulos e combinações novas no meu corpo, detalhes que a priori são fiapos e que podem fazer florescer um caminho inteiro.

Eu esperava. Eu esperava que tudo se juntasse e saltasse de dimensão. Que fôssemos merecedoras da benção da síntese. Cartazes pregados na parede com a ordem das cenas, os títulos das cenas, das unidades e dos movimentos, o labirinto de giz que ia se apagando até o fim do ensaio, o trabalho brilhante e essencial da Elisete Jeremias correndo discretamente, facilitando tudo, pondo as coisas todas nos devidos lugares, preparando o espaço, tornando a caminhada possível. E a certa altura as máscaras foram chegando. Que importante aquele dia que fomos tirar fotos pra divulgação e tivemos alguma idéia de como nossas queridas sombras Elizabeth e Maria se vestiam!!! E os cabelos, e o corpete, companheiro desde o começo do processo, e a delicadeza dos tecidos e a bota de montaria. É sempre uma alegria conhecer esses elementos que parecem tão externos à criação $e$ na verdade fazem encaixar peças soltas dentro do ator, ou até o inspiram numa direção inesperada. A primeira vez que eu e Bel sentamos em nossos "troninhos de madeira" processos internos se aceleraram em nós. Simone e sua equipe não foram artistas só na concepção e execução dos elementos materiais da arte do espetáculo, mas parceiros verdadeiros, desde a apresentação das idéias (momento que foi por si só uma injeção de beleza e alma no cotidiano dos ensaios) até os instantes antes da estréia, a escuta atenta para as pequenas e grandes necessidades e ansiedades das atrizes.

Então foi bem assim. A verdade bem clara. $\mathrm{O}$ encontro de repertórios. Aquele respeito máximo pelo território da outra, a curiosidade enorme pelo território da outra, uma permeabilidade grande para invasões e compartilhamentos de territórios. A brincadeira da competição correndo solta entre nós atrizes e desembocan- do na cena. Mas em algumas encruzilhadas do caminho, minha criança insegura chorou: "Ela é a forte, eu sou a fraca. Estou perdida, vou ser esmagada”. E tive que reagir com o bom humor sempre necessário na criação, e brincar com ela, sem afrontá-la, porque ela é forte mesmo. Eu, Elizabeth, apavorada com os encantos de Maria.

Cibele, com muita paciência e delicade$\mathrm{za}$, norteou tudo que girava selvagem no ar. Quando eu e Bel mais achávamos que as decisões estavam conosco, e que éramos super independentes, éramos surpreendidas por diretrizes claríssimas dela que mudavam radicalmente o curso de uma cena em desenvolvimento, muitas vezes pedidos que ela fazia sobre o tom de uma fala, ou sobre um rearranjo no texto, que a primeira vista pareciam desnecessários ou equivocados, logo se mostravam praticamente óbvios. Cibele ficava atrás da gente (literalmente) como uma vozinha da consciência, daquelas nem sempre agradáveis de se ouvir, mas sempre bem vinda. Durante todo o processo esteve em cena conosco, puxando a nossa energia, acalmando nosso coração ou nos enlouquecendo. Foi difícil, em determinados momentos, nos quais estávamos num trabalho inesperadamente complexo de "decorar" nossas próprias palavras, conseguir lidar com muita informação que nos era lançada por ela. Aos poucos fui me acostumando e entendendo que a pressão era inevitável. Nosso tempo era curto, e ela sabia que conseguiríamos absorver aos poucos os pontos essenciais da direção. Pelo menos em certo momento me tranqüilizou pensar assim. Que ela confiava em mim e por isso exigia, delicadamente, aquela doçura incrível, que a minha paixão não esfriasse e que, da maneira que fosse possível, eu seguisse tentando juntar os cacos.

A luz nos coroou. Sabíamos mais ou menos o que viria, eu e Bel já trabalhamos com a Alessandra Domingues em outros espetáculos e durante os ensaios, algumas vezes as próprias improvisaçôes solicitavam movimentos de luz, outras vezes ela própria nos adiantava alguma coisa do que viria. Dez dias antes da estréia, aproximadamente, é que a luz começou a ser 
montada e fomos assistindo às imagens atingindo outro grau de poesia. Durante toda a primeira temporada detalhes de operação foram modificados, mas já estava tudo lá, contracenando conosco de maneira bem direta. Um trabalho bem generoso.

Uma garantia que tínhamos o tempo todo era de que as energias que seriam movidas com esse trabalho seriam as do coração.

\section{Detalhes}

As mãos.

Elizabeth: o esmalte, o ângulo aberto do pulso, as mãos nas cristas ilíacas. Os braços serpenteados próximos ao corpo.

Maria: as patas grandes e frágeis do cavalo ferido tentando se agarrar em algum pedaço do céu.

As pernas.

Elizabeth: as botas. Os pés que desenham os caminhos da serpente. A base firme.

Maria: as pernas fracas do animal no cativeiro. Cambaleante.
A coluna.

Elizabeth: o nunca flexioná-la, o peito aberto, a cervical alongada, a torção, o ligeiro torcicolo de quem também teme o machado, de quem tem que endurecer para agüentar.

Maria: tentativa de manter vértebra sobre vértebra, o desequilíbrio, o perigo da queda, o despencamento, a moribunda.

Brincamos muito de cavalinho ferido e serpente.

O cavalinho da Bel, cativante e aflitivo, pronto pra ser envenenado e devorado. A história de vida dela tão diferente da minha se encaixando nas lacunas da minha experiência. O tempo todo confiança no corpo dela, no amor dela.

E ele. Henrique Mariano, presente em momentos cruciais dos ensaios, botando tudo em dúvida, nos obrigando a tomar partido das nossas certezas. Rigoroso: como as leis do coração. Como o público a ser conquistado.

Elizabeth, o que eu tenho mesmo a dizer é que o meu amor é pela vida da terra e seus filhos. E sei que o seu também é. Outras terras, outros filhos. 